\title{
Additional Commentary on the Detection and Quantification of Plastic Micro- and Nanoparticles in Tea Samples
}

\author{
Jessica Caldwell ${ }^{\mathrm{a}}$ Patricia Taladriz-Blanco ac, Barbara Rothen-Rutishausera ${ }^{\mathrm{a}}$, and Alke Petri-Fink ${ }^{\mathrm{ab} *}$
}

\begin{abstract}
The study of plastic particles, particularly those in the micro-, sub-micro-, and nano-size ranges, within food and beverages has gained increasing interest within recent years. However, many analytical techniques have limits of detection which hinder their use for the study of these particles in these sample matrices. In addition, remaining contaminants from the matrices can interfere with the signals from plastic particles. Thus, great care must be given to sample preparation and data interpretation to ensure accurate results. This study proposes the use of sample purification through chemical digestion protocols to facilitate the study of plastic particles present in tea samples, and serves to highlight technical limitations which must be overcome in future studies.
\end{abstract}

Keywords: Beverages · Food · Microplastic · Nanoplastic

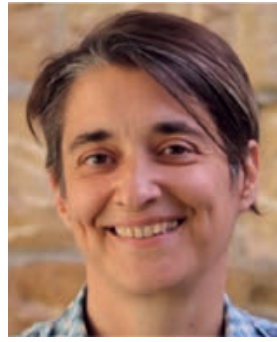

Prof. Alke Petri-Fink received her $\mathrm{PhD}$ in chemistry from the University of Ulm, Germany in 1999. After a post-doctoral fellowship at the University of Gainesville, Florida, she joined the Institute of Materials Science at the École Polytechnique Fédérale de Lausanne (EPFL), first as a post-doctoral researcher, then as a senior scientist. She became an Associate Swiss National Science Foundation Professor in the Department of Chemistry at the University of Fribourg in 2009, and a Full Professor in 2011 at the Adolphe Merkle Institute, Switzerland. Her research focuses on inorganic nanoparticles, their synthesis, surfaces, and interactions with biological cells.

\section{Introduction}

Of the 368 million tons of plastics produced in 2020, 39.6\% (approximately 145.7 million tons) were utilized in packaging materials. ${ }^{11]}$ Commonly, such packaging is utilized to preserve food and beverage products meant for human consumption. Many recent studies report the subsequent transmission of plastic particles with sizes in the micro- $(5 \mathrm{~mm}-1 \mu \mathrm{m})$, sub-micro $(1$ $\mu \mathrm{m}-100 \mathrm{~nm})$, and even nano- $(<100 \mathrm{~nm})$ ranges into the products that are contained within such plastic packaging. However, to date, the study of nanoplastic particles in analytically complex sample matrices (i.e. those that contain high amounts of additional organic or inorganic matter) is plagued by a multitude of challenges which arise from their predominantly carbon-based chemical structure, low densities, small sizes, and low estimated concentrations within relevant samples. Thus, studies tend to focus on larger microplastic particle presence, and have reported their detection in a variety of food and beverage products such as bottled water ${ }^{[2]}$ and beers. ${ }^{[3]}$ While this data serves to highlight the importance of quantifying the presence of plastic particles within products meant for human consumption, it fails to ac- curately represent the most analytically challenging fraction of plastic particles: nanoplastics.

Research groups such as Hernandez et al. ${ }^{[4]}$ have attempted to address this knowledge gap through the study of micro-, sub-micro-, and nanoplastic particles reported to leach from teabags into tea after the hydrolytic degradation ${ }^{[5]}$ of the polymer chains present in the plastics that the teabags are composed of. However, many of the standard techniques utilized in the literature have limitations that hinder the accurate collection and interpretation of data; such as the limit of detection commonly reported for Fourier transform infrared spectroscopy (FTIR) being orders of magnitude larger (i.e. $\sim 10 \mu \mathrm{m}$ minimum particle size ${ }^{[6]}$ ) than the nanoplastic particles of interest or the difficulty differentiating true plastic particles from other organic materials in scanning electron microscopy (SEM) images. ${ }^{[7]}$ Such concerns have previously been expressed by Busse et al., who highlighted the potential for the results reported by Hernandez et al. to be skewed by the presence of contaminants such as oligomers that would not be differentiated from true plastic particles by FTIR due to the area averaging quality of the measurements, or in SEM images due to oligomer crystallization upon drying. ${ }^{[7]}$ Thus, the aim of this study is to further probe the limit of these techniques for the detection of plastic particles in analytically complex sample matrices such as foods and beverages, and to attempt to augment the data one can obtain through the introduction of additional controls and purification steps like the chemical digestion of contaminants previously reported in the literature. ${ }^{[8]}$

\section{Results and Interpretation}

Commercial teabag samples were prepared through cutting and rinsing and the recovered tea leaves were steeped as a control as reported by Hernandez et al. ${ }^{[4]}$ Additional controls were prepared utilizing plastic teabags, which had never contained tea leaves, and are henceforth referred to as 'empty control'. SEM images obtained using a Mira3 LM FE scanning electron microscope 
(Tescan, Czech Republic) for the teabags before and after the steeping protocol (Fig. 1) yielded similar results to those reported by Hernandez et al. ${ }^{[4]}$ Namely, small particles could be found on the surface of non-steeped teabags which were not present on the surface of steeped teabags, and surface roughness could be seen for steeped teabags. However, it was noted that areas with higher surface roughness could also be observed in the non-steeped teabags and that particles could still be observed on the surface of steeped teabags. Thus, the potential that some defects may be present from manufacturing should be considered. Additionally, SEM images of procedural blank samples (i.e. MilliQ water which was boiled, filtered, dialyzed, digested, and handled in the same manner as true samples) which were prepared under the same conditions reported by Hernandez et al. were shown to contain trace amounts of particle contaminants (i.e. from atmospheric deposition) when imaged at low magnification (Fig. 1). Thus, while the cut teabag leachates showed what appeared to be particles in size ranges similar to those reported by Hernandez et al., ${ }^{[4]}$ the exact composition of these particle-like materials requires further investigation. The need for such investigation is further highlighted by Busse et al. in their recent commentary, ${ }^{[7]}$ where they discuss the potential for the particle-like materials present in SEM images to be crystallized oligomers, or contaminants as a result of sample handling and preparation.
With this in mind, ATR-FTIR spectra were collected for the commercial teabags in addition to multiple controls (Fig. 2; Table 1) using a Perkin Elmer universal attenuated total reflection (UATR) accessory and pressure arm. The commercial teabag spectra and the empty teabag control matched with a Nylon 6 reference polymer spectrum present in the Perkin Elmer Spectra 10 reference database (Table 2). However, the spectra for the cut commercial teabag leachates ('Commercial Leachate' in Fig. 2) had extra peaks that were not observed in the spectra obtained from the non-steeped commercial teabags. These peaks are present even after the completion of the full purification process (i.e. filtration with a cellulose $2.5 \mu \mathrm{m}$ cutoff Whatmann filter, 5-7 day dialysis with a $14 \mathrm{kDa}$ cutoff membrane from Carl Roth $\mathrm{GmbH}$ $+\mathrm{Co}$ ). Some of these additional peaks (e.g. at $\sim 1,012 \mathrm{~cm}^{-1}$ ) have been reported by Oh et al. ${ }^{[10]}$ to appear in the FTIR spectra obtained for cellulose as a result of the presence of $-\mathrm{OH}$ bonds in the cellulose backbone and may be attributed to the presence of contaminants from the filter paper, atmospheric deposition, or organic matter left in the teabags after the rinsing protocol. Other additional peaks observed are reported in a study by Cai et al. to be present in tea samples; with specific bands near $1,600 \mathrm{~cm}^{-1}$ reported to be the result of ring stretching from sugars and/or $\mathrm{N}-\mathrm{H}$ and $\mathrm{C}-\mathrm{O}$ bond vibrations from carboxyl groups, near 1,000-1,100 $\mathrm{cm}^{-1}$ reported to be characteristic of the $\mathrm{O}$-substituted glucose residues in
Fig. 1. SEM images of the commercial teabags before $(A)$ and after (B) steeping, the empty nylon control teabags before (C) and after (D) steeping, the initial procedural blank leachate (i.e. after boiling, filtration, and dialysis) (E) and the procedural blank after a 7-day $\mathrm{KOH}$ digestion (F) show the presence of trace amounts of particles (indicated with white arrows). Insets for the procedural blanks show particles at a higher magnification.
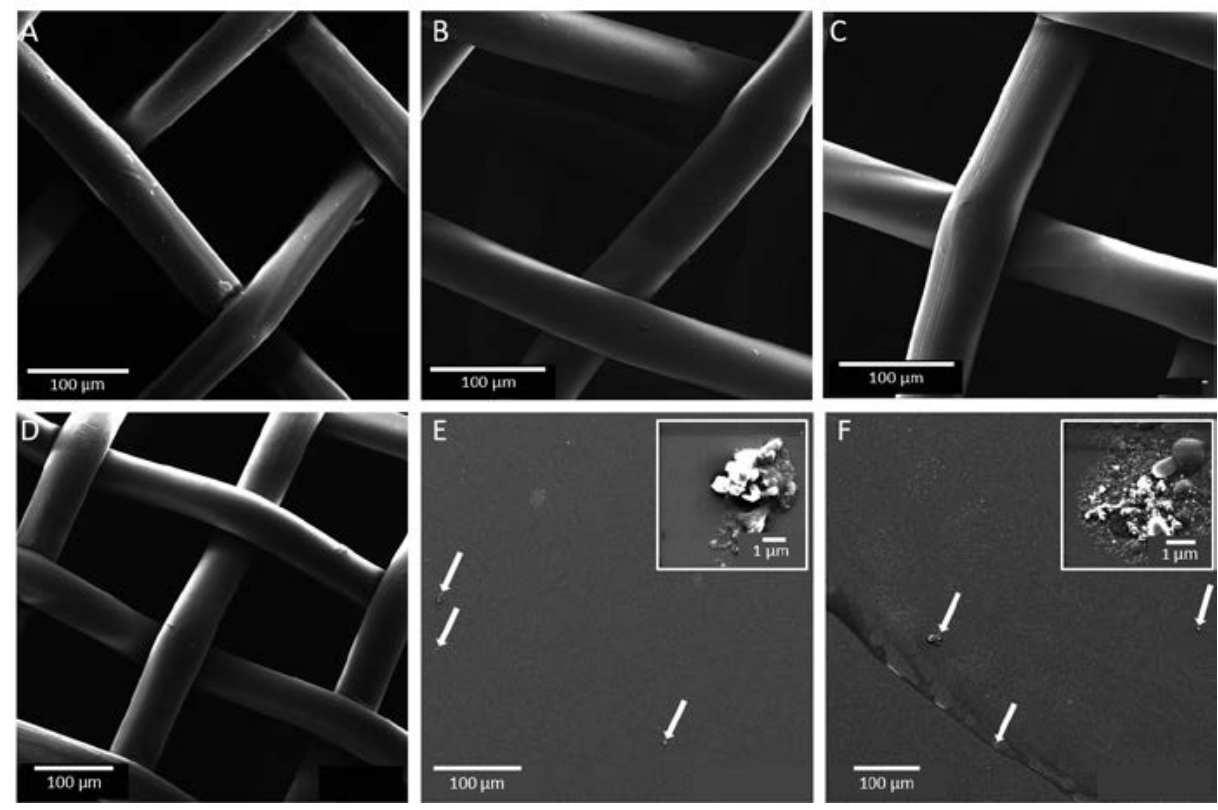
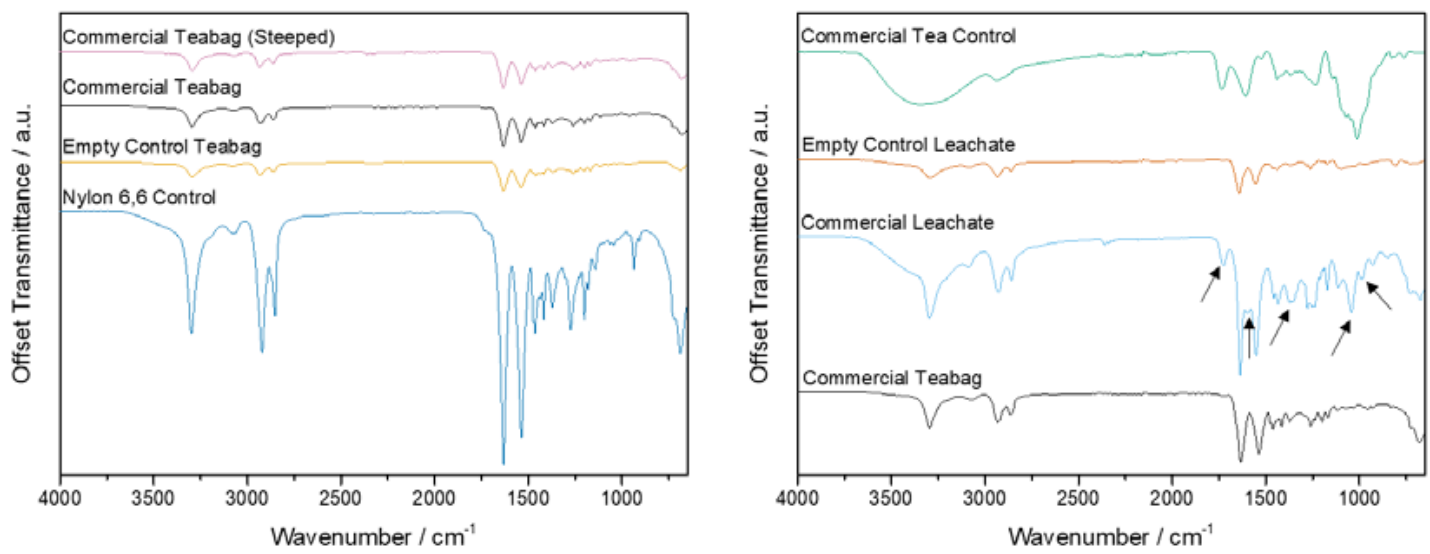

Fig. 2. FTIR data for the representative commercially available teabag and its leachate compared to spectra from relevant controls. All spectra were obtained by averaging 10 scans over the wavenumber range of $650-4,000 \mathrm{~cm}^{-1}$ with a spectral resolution of $4 \mathrm{~cm}^{-1}$. Extra peaks present in the commercial teabag leachate are indicated with black arrows. 
Table 1. Peak assignments for peaks anticipated to be in the FTIR spectra obtained from samples that are Nylon- based. ${ }^{\left[{ }^{9}\right]}$

Wavenumber $\left(\mathrm{cm}^{-1}\right)$

$3,000-2,780$

$1,480-1,400$

$1,350-1,200$

$1,124-1,020$

960-930

$\sim 690$

\section{Samples Containing Peak}

Nylon 6,6 Control; Empty Teabag Control and Leachate; Commercial teabag

Nylon 6,6 Control; Empty Teabag Control and Leachate; Commercial teabag

Nylon 6,6 Control; Empty Teabag Control and Leachate; Commercial teabag

Nylon 6,6 Control; Empty Teabag Control and Leachate; Commercial teabag

Nylon 6,6 Control; Empty Teabag Control and Leachate; Commercial teabag

Nylon 6,6 Control; Empty Teabag Control and Leachate; Commercial teabag

Nylon 6,6 Control; Empty Teabag Control and Leachate; Commercial teabag

Nylon 6,6 Control; Empty Teabag Control and Leachate; Commercial teabag

Nylon 6,6 Control; Empty Teabag Control and Leachate; Commercial teabag

Nylon 6,6 Control; Empty Teabag Control and Leachate; Commercial teabag

\section{Assignment}

$\mathrm{N}-\mathrm{H}$ stretching vibration

C-H symmetric stretching vibration

$\mathrm{C}=\mathrm{O}$ stretching vibration (amide $\mathrm{I}$ )

$\mathrm{N}-\mathrm{H}$ bending; $\mathrm{C}-\mathrm{N}$ stretching vibrations (amide II)

$\mathrm{CH}_{2}$ symmetric (scissor) deformation

$\mathrm{N}-\mathrm{H}$ deformation (amide III)

CONH skeletal vibrations

$\mathrm{C}-\mathrm{C}$ and $\mathrm{CONH}$ skeletal vibrations

CONH skeletal vibrations

$\mathrm{N}-\mathrm{H}$ wagging
Table 2: A summary of the similarity of chemical fingerprints of various tested materials obtained through automated correlation analysis.

\begin{tabular}{l|l|l} 
Sample 1 & Sample 2 & Correlation \\
\hline $\begin{array}{l}\text { Empty Control } \\
\text { Teabag }\end{array}$ & $\begin{array}{l}\text { Pure Nylon } \\
\text { Reference Spectra }\end{array}$ & $96 \%$ \\
\hline $\begin{array}{l}\text { Empty Control } \\
\text { Teabag }\end{array}$ & $\begin{array}{l}\text { Empty Control } \\
\text { Leachate }\end{array}$ & $79 \%$ \\
\hline $\begin{array}{l}\text { Empty Control } \\
\text { Leachate }\end{array}$ & $\begin{array}{l}\text { Pure Nylon } \\
\text { Reference Spectra }\end{array}$ & $75 \%$ \\
\hline $\begin{array}{l}\text { Commercial } \\
\text { Teabag }\end{array}$ & $\begin{array}{l}\text { Pure Nylon } \\
\text { Reference Spectra }\end{array}$ & $93 \%$ \\
\hline $\begin{array}{l}\text { Commercial } \\
\text { Teabag }\end{array}$ & $\begin{array}{l}\text { Commercial } \\
\text { Teabag Leachate }\end{array}$ & $30 \%$ \\
\hline $\begin{array}{l}\text { Commercial } \\
\text { Teabag Leachate }\end{array}$ & $\begin{array}{l}\text { Commercial } \\
\text { Steeped Tea }\end{array}$ & $44 \%$ \\
\hline $\begin{array}{l}\text { Empty Control } \\
\text { Teabag }\end{array}$ & $\begin{array}{l}\text { Commercial } \\
\text { Teabag }\end{array}$ & $96 \%$ \\
\hline $\begin{array}{l}\text { Commercial } \\
\text { Teabag Leachate }\end{array}$ & $\begin{array}{l}\text { Empty Control } \\
\text { Leachate }\end{array}$ & $18 \%$ \\
\hline $\begin{array}{l}\text { Empty Control } \\
\text { Leachate 1:1 KOH }\end{array}$ & $\begin{array}{l}\text { Empty Control } \\
\text { Teabag }\end{array}$ & $14 \%$ \\
\hline Days & & \\
\hline
\end{tabular}

tea polysaccharides, and within the ranges of 1,700 to $1,460 \mathrm{~cm}^{-1}$ and 800 to $500 \mathrm{~cm}^{-1}$ as the result of various tea polysaccharides.[11] Such results appear to indicate the presence of small tea leaf frag- ments or other contaminants within the samples even after the washing, filtration, and dialysis steps utilized in the sample purification protocol.

In order to be able to more accurately determine the number of particles present in the cut teabag leachates that were truly plastic-based, steps were made to develop a protocol for the chemical digestion of particulate organic matter from tea leaves. As it was previously reported in the literature that potassium hydroxide $(\mathrm{KOH})$ gave high digestion efficiencies for animal tissue with minimal damage to microplastic particles ${ }^{[8 \mathrm{a}]}$ and that hydrogen peroxide $\left(\mathrm{H}_{2} \mathrm{O}_{2}\right)$ yielded the highest digestion efficiencies for vegetal matter ${ }^{[8 b]}$ these were the chemicals selected for initial testing. For both $\mathrm{KOH}$ and $\mathrm{H}_{2} \mathrm{O}_{2}$, a digestion period of 48 hours was shown to be insufficient for the removal of organic matter present in tea samples. The sample digested with $\mathrm{H}_{2} \mathrm{O}_{2}$ for 7 days also yielded unsatisfactory results, but after a 7-day digestion with $\mathrm{KOH}$ it appeared that some organic matter may have been digested out of the sample. However, key peaks found in the initial tea control spectra could still be seen, albeit at lower intensities, in the chemical fingerprint of the digested samples. Additionally, when the leachate obtained from steeping the empty control teabags was digested under these conditions, a severe drop in the correlation value with the teabag was observed (Table 2; Fig. 3). This indicates that attempts to chemically degrade the components from tea will additionally degrade the plastic-based oligomers, but may also damage any plastic particles present within the sample. Such findings have been reported frequently in the literature for plastic particles composed of Nylon (i.e. polyamide) and poly(ethylene terephthalate $)^{[8 \mathrm{a}, 12]}$ due to the potential for the polymer chains that compose these materials to hydrolyze in aqueous environments. ${ }^{[5]}$

\section{Conclusions}

For the teabag types analyzed during the current study, it is likely that the leachate obtained from steeping the cut, rinsed commercial teabags is a mixture of plastic-based materials and other 

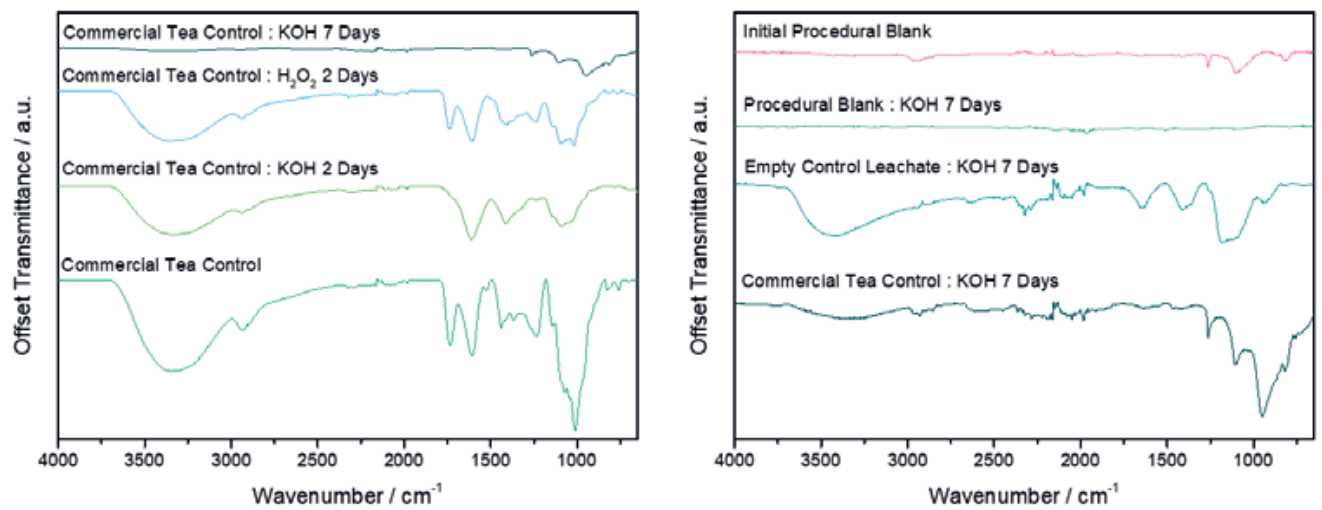

Fig. 3. FTIR data for the representative commercially available tea control and the empty control teabag leachate after chemical digestion. Additional comparisons are made to procedural blank data collected before and after the most promising chemical digestion protocol. All spectra were obtained by averaging 10 scans over the wavenumber range of $650-4,000 \mathrm{~cm}^{-1}$ with a spectral resolution of $4 \mathrm{~cm}^{-1}$.

organic contaminants such as tea leaf-based particulate matter or dust. This hypothesis is supported by the literature ${ }^{[7]}$ in addition to poor matches between the FTIR spectra of the teabags and the leachates, and the presence of trace amounts of particulate matter detected within the SEM imaging controls. However, the techniques tested in this study were shown to be incapable of resolving the chemical contents of the leachate samples on a single particle or single material basis, and the chemical digestions were shown to degrade organic contaminants in addition to potential plastic-based contaminants. Thus, while a qualitative sample analysis could be achieved, no quantitative data can be accurately reported. The authors encourage future studies to be conducted only after careful consideration of the data presented within the field, and with the plans for further optimization of sample pre-processing (e.g. digestion with enzymes to ensure no plastic degradation $\left.{ }^{[13]}\right)$ and/or analytics (e.g. through the introduction of more analytically sensitive techniques such as SERS ${ }^{[14]}$, which may allow for the analysis of samples in a single-particle or single material basis.

\section{Acknowledgements}

J.C. and A.P.-F. acknowledge funding from the Swiss National Science Foundation (200020_184635) and the Federal Food Safety and Veterinary Office (FSVO). All authors would like to thank the Adolphe Merkle Foundation for providing funding. Additionally, this work benefitted from support from the Swiss National Science Foundation through the National Center of Competence in Research Bio-Inspired Materials.

Received: June 28, 2021

[1] PlasticsEurope, 'Plastics - the Facts 2020 an Analysis of European Plastics Production, Demand and Waste Data'Brussels - Belgium, 2020.

[2] S. A. Mason, V. G. Welch, J. Neratko, Front. Chem. 2018, 6 , https://doi.org/10.3389/fchem.2018.00407.

[3] G. Liebezeit, E. Liebezeit, Food Add. Contamin. A 2014, 31, 1574, https://doi.org/10.1080/19440049.2014.945099.

[4] L. M. Hernandez, E. G. Xu, H. C. E. Larsson, R. Tahara, V. B. Maisuria, N. Tufenkji, Environ. Sci. Technol. 2019, 53, 12300, https://doi.org/10.1021/acs.est.9b02540.

[5] B. Gewert, M. M. Plassmann, M. MacLeod, Environ. Sci. Proc. Impacts 2015, 17, 1513, https://doi.org/10.1039/C5EM00207A

[6] A. Käppler, D. Fischer, S. Oberbeckmann, G. Schernewski, M. Labrenz, K.-J. Eichhorn, B. Voit, Anal. Bioanal. Chem. 2016, 408, 8377, https://doi.org/10.1007/s00216-016-9956-3.

[7] K. Busse, I. Ebner, H.-U. Humpf, N. Ivleva, A. Kaeppler, B. E. Oßmann, D. Schymanski, Environ. Sci. Technol. 2020, 54, 14134, https://doi.org/10.1021/acs.est.0c03182.
[8] a) A. Karami, A. Golieskardi, C. K. Choo, N. Romano, Y B. Ho, B. Salamatinia, Sci. Total Environ. 2017, 578, 485, https://doi.org/10.1016/j.scitotenv.2016.10.213; b) A. Herrera, P. Garrido-Amador, I. Martínez, M. D. Samper, J. López-Martínez, M. Gómez, T. T. Packard, Marine Poll. Bull. 2018, 129, 61, https://doi.org/ 10.1016/j.marpolbul.2018.02.015.

[9] a) G. Socrates, 'Infrared and Raman characteristic group frequencies: tables and charts', John Wiley \& Sons, 2004; b) I. Noda, A. E. Dowrey, J. L. Haynes, C. Marcott, in 'Physical Properties of Polymers Handbook', Ed. J. E. Mark, Springer New York, New York, NY, 2007, p. 395, https://doi.org/10.1007/978-0-387-69002-5_22; c) G. Rotter, H. Ishida, $J$. Polym. Sci. B 1992, 30, 489, https://doi.org/10.1002/polb.1992.090300508.

[10] S. Y. Oh, D. I. Yoo, Y. Shin, G. Seo, Carbohyd. Res. 2005, 340, 417, https://doi.org/10.1016/j.carres.2004.11.027.

[11] J.-X. Cai, Y.-F. Wang, X.-G. Xi, H. Li, X.-L. Wei, Int. J. Biol. Macromol. 2015, 78, 439, https://doi.org/10.1016/j.ijbiomac.2015.03.025.

[12] a) F. Ribeiro, E. D. Okoffo, J. W. O'Brien, S. Fraissinet-Tachet, S. O'Brien, M. Gallen, S. Samanipour, S. Kaserzon, J. F. Mueller, T. Galloway, K. V. Thomas, Environ. Sci. Technol. 2020, 54, 9408, https://doi.org/10.1021/acs.est.0c02337; $\quad$ b) M. Scheurer, M. Bigalke, Environ. Sci. Technol. 2018, 52, 3591 , https://doi.org/10.1021/acs.est.7b06003.

[13] a) A. Dehaut, A.-L. Cassone, L. Frère, L. Hermabessiere, C. Himber, E. Rinnert, G. Rivière, C. Lambert, P. Soudant, A. Huvet, G. Duflos, I. Paul-Pont, Environ. Poll. 2016, 215, 223 , https://doi.org/10.1016/j.envpol.2016.05.018; b) W. Courtene-Jones, B Quinn, F. Murphy, S. F. Gary, B. E. Narayanaswamy, Anal. Meth. 2017, 9, 1437, https://doi.org/10.1039/C6AY02343F.

[14] J. Langer, D. Jimenez de Aberasturi, J. Aizpurua, R. A. Alvarez-Puebla, B. Auguié, J. J. Baumberg, G. C. Bazan, S. E. J. Bell, A. Boisen, A. G. Brolo, J. Choo, D. Cialla-May, V. Deckert, L. Fabris, K. Faulds, F. J. García de Abajo, R. Goodacre, D. Graham, A. J. Haes, C. L. Haynes, C. Huck, T. Itoh, M. Käll, J. Kneipp, N. A. Kotov, H. Kuang, E. C. Le Ru, H. K. Lee, J.-F. Li, X. Y. Ling, S. A. Maier, T. Mayerhöfer, M. Moskovits, K. Murakoshi, J.-M Nam, S. Nie, Y. Ozaki, I. Pastoriza-Santos, J. Perez-Juste, J. Popp, A. Pucci, S. Reich, B. Ren, G. C. Schatz, T. Shegai, S. Schlücker, L.-L. Tay, K. G. Thomas, Z.-Q. Tian, R. P. Van Duyne, T. Vo-Dinh, Y. Wang, K. A. Willets, C. Xu, H. Xu, Y. Xu, Y. S. Yamamoto, B. Zhao, L. M. Liz-Marzán, ACS Nano 2020, 14, 28, https://doi.org/10.1021/acsnano.9b04224.

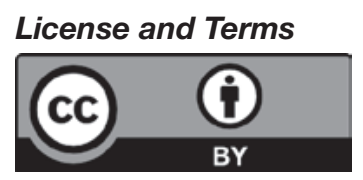

This is an Open Access article under the terms of the Creative Commons Attribution License CC BY 4.0. The material may not be used for commercial purposes.

The license is subject to the CHIMIA terms and conditions: (http:// chimia.ch/component/sppagebuilder/?view=page\&id=12).

The definitive version of this article is the electronic one that can be found at https://doi.org/10.2533/chimia.2021.882 